Correspondence

Simone J. Séror

simone.seror@igmors.u-psud.fr

Received 27 November 2010 Revised 9 April 2011

Accepted 17 May 2011

\section{Single-cell analysis in situ in a Bacillus subtilis swarming community identifies distinct spatially separated subpopulations differentially expressing hag (flagellin), including specialized swarmers}

\author{
Kassem Hamze, ${ }^{1} \dagger$ Sabine Autret, ${ }^{1}$ Krzysztof Hinc, ${ }^{1,2}$ Soumaya Laalami, ${ }^{3}$ \\ Daria Julkowska, ${ }^{1} \ddagger$ Romain Briandet, ${ }^{4}$ Margareth Renault, ${ }^{4}$ \\ Cédric Absalon, ${ }^{1} \S$ I. Barry Holland, ${ }^{1}$ Harald Putzer $^{3}$ and Simone J. Séror ${ }^{1}$ \\ ${ }^{1}$ Université Paris-Sud, Institut de Génétique et Microbiologie, UMR CNRS 8621, Bât. 409, \\ 91405 Orsay Cedex, France \\ ${ }^{2}$ Medical University of Gdansk, Debinki 1, 80-211, Department of Medical Biotechnology, \\ Intercollegiate Faculty of Biotechnology, Gdansk, Poland \\ ${ }^{3}$ CNRS UPR9273, Institut de Biologie Physico-Chimique, 13 rue Pierre et Marie Curie, \\ 75005 Paris, France \\ ${ }^{4}$ INRA, UMR1319 MICALIS, Jouy-en-Josas, France
}

\begin{abstract}
The non-domesticated Bacillus subtilis strain 3610 displays, over a wide range of humidity, hyperbranched, dendritic, swarming-like migration on a minimal agar medium. At high (70\%) humidity, the laboratory strain $168 \mathrm{sfp}^{+}$(producing surfactin) behaves very similarly, although this strain carries a frameshift mutation in $s w r A$, which another group has shown under their conditions (which include low humidity) is essential for swarming. We reconcile these different results by demonstrating that, while swrA is essential for dendritic migration at low humidity (30-40\%), it is dispensable at high humidity. Dendritic migration (flagella- and surfactin-dependent) of strains $168 \mathrm{sfp}^{+} \mathrm{swr} A$ and 3610 involves elongation of dendrites for several hours as a monolayer of cells in a thin fluid film. This enabled us to determine in situ the spatiotemporal pattern of expression of some key players in migration as dendrites develop, using $g f p$ transcriptional fusions for hag (encoding flagellin), $\operatorname{com} A$ (regulation of surfactin synthesis) as well as eps (exopolysaccharide synthesis). Quantitative (singlecell) analysis of hag expression in situ revealed three spatially separated subpopulations or cell types: (i) networks of chains arising early in the mother colony (MC), expressing eps but not hag; (ii) largely immobile cells in dendrite stems expressing intermediate levels of hag; and (iii) a subpopulation of cells with several distinctive features, including very low com $A$ expression but hyper-expression of hag (and flagella). These specialized cells emerge from the MC to spearhead the terminal $1 \mathrm{~mm}$ of dendrite tips as swirling and streaming packs, a major characteristic of swarming migration. We discuss a model for this swarming process, emphasizing the importance of population density and of the complementary roles of packs of swarmers driving dendrite extension, while non-mobile cells in the stems extend dendrites by multiplication.
\end{abstract}

tPresent address: University of Lebanon, Faculty of Science, Section 1, Beirut, Lebanon.

‡Present address: Plateforme Maladies Rares, GIS Institut des Maladies Rares, 96 rue Didot, 75014 Paris, France.

§Present address: Children's Hospital Boston, Division of Infectious Disease, Boston, MA 02115, USA.

Abbreviations: a.u., arbitrary units; MC, mother colony.

Supplementary Methods, eight supplementary figures and three supplementary movie files are available with the online version of this paper.

\section{INTRODUCTION}

The formation of bacterial communities, such as Bacillus subtilis colonies, was shown recently, while this work was in progress, to occur through a developmental-like program, associated with the presence of different cell types (see Vlamakis et al., 2008; Lemon et al., 2008; López \& Kolter, 2010). Another form of community swarming migration over a surface, apparently occurring in thin fluid films, requires flagella, a surfactant and the production of specialized swarmer cells (Harshey, 2003; Darnton et al., 2010). 
Studies of swarming to date have primarily involved Gramnegative bacteria on rich media or minimal media fortified with Casamino acids. Most studies have concerned the migration of Proteus mirabilis as waves of confluent expansion over hard agar (2\%), involving coordinated movement of very large clusters of aligned swarmers extremely long, profusely flagellated filamentous cells - at the swarm front (Bisset, 1973; Fraser \& Hughes, 1999). Serratia liquefaciens swarmers, however, appear to be only moderately elongated, although profusely flagellated (Eberl et al., 1999). In contrast, in Escherichia coli and Salmonella typhimurium (Darnton et al., 2010; Turner et al., 2010; Harshey, 2003), migration is restricted to softer agar (around $0.5 \%$ ), and involves smaller clusters (packs) of swarmers that are only moderately elongated and flagellated (two- to threefold in each case). In Pseudomonas aeruginosa, swarming takes the form of unbranched dendrites or tendrils, rather than confluent fields, and swarmers are around twofold larger than vegetative cells, with two flagella rather than one (Rashid \& Kornberg, 2000; Caiazza et al., 2005). Finally, particularly in E. coli, coordinated movement appears to be achieved through alignment of around five cells into groups or packs (McCarter, 2010, and the Rowland Institute at Harvard website cited therein).

The most studied example of swarming in Gram-positive bacteria is that of B. subtilis. Swarming is limited to 0.7$1 \%$ agar, and is absolutely dependent upon the presence of flagella (Kearns \& Losick, 2003; Julkowska et al., 2005; Hamze et al., 2009) and the production of surfactin, which spreads 1-2 $\mathrm{mm}$ ahead of the advancing swarm front (Kearns \& Losick, 2003; Julkowska et al., 2004, 2005; Debois et al., 2008). Two types of swarming-like migration by B. subtilis have been described. On Luria broth (LB) agar at low humidity and $37{ }^{\circ} \mathrm{C}$ (primarily analysed with nondomesticated strains such as 3610 ), migration proceeds as an expanding confluent field, headed by small groups of bacteria, apparently with little change in individual size (Kearns \& Losick, 2003; Julkowska et al., 2004). In contrast, we have described the formation of hyper-branched dendritic patterns by strain 3610 on the minimal B medium at both high and low humidity, which develop through a series of well-defined stages (Julkowska et al., 2004). We have also observed very similar behaviour for the $s f p^{+}$derivative of the laboratory strain 168 (able to produce surfactin) at high humidity, although the cells fail to swarm reproducibly at low humidity. This strain in fact carries a mutation in swrA (Kearns et al., 2004; Hamze et al., 2009), a gene of unknown function implicated in activation of transcription of the large fla/che operon (Kearns \& Losick, 2006). swrA has been reported (apparently at low humidity) to be essential for swarming migration on rich medium (Kearns et al., 2004). Recently, Patrick \& Kearns (2009) have also reported that strain 168 $s f p^{+} s w r A$ fails to show surface migration on B medium under their conditions. Those authors, from their results, claim that dendritic migration of strain $168 s f p^{+} s w r A$ at
$70 \%$ humidity can only be explained by 'sporadic' in situ reversion to $s w r A^{+}$, or, surprisingly, they imply that dendritic migration involves a form of swimming in surface water and not swarming. Unfortunately, they did not control humidity in their studies and therefore failed adequately to test its effect on the migration of strain 168 $s f p^{+} s w r A$. One objective of this study was to reconcile these apparently contradictory results. We have done this by confirming that swrA is required for migration at low humidity, but is dispensable at high humidity, without reversion to $s w r A^{+}$. We also show that both $168 s f p^{+} s w r A$ and an $s w r A^{+}$derivative produce very similar dendritic migration at high humidity. In addition, we present several lines of evidence to show that dendritic migration of the laboratory strain $168 s \mathrm{fp}^{+} s w r A$, like the migration of $s w r A^{+}$strains, does not involve swimming of individuals in a large volume of surface water, but instead is like classical swarming in being restricted to a thin film.

Dendritic migration of strain $168 s f p^{+} s w r A$ involves distinct morphological and genetically defined stages at high humidity (Julkowska et al., 2004, 2005; Hamze et al., 2009). Thus, following the first visible indication of initiation of migration, a spreading zone of surfactin emanating from the mother colony (MC; the site of inoculation), several small bud-like structures burst outwards from the edge of the MC. Importantly, a characteristic feature of dendritic migration is an advancing monolayer of cells that form the developing buds and primary dendrites up to about $1.5 \mathrm{~cm}$ in length, before the switch to multilayering and finally the formation of hyper-branched fractal-like patterns (Julkowska et al., 2004, 2005; Hamze et al., 2009). This form of community development is of interest to mathematicians and physicists studying pattern formation (Marrocco et al., 2010), while the initial several hours of development of the swarm as a monolayer provide a highly convenient system for molecular geneticists to analyse gene expression in situ at the single-cell level.

Since the development of the dendritic community of $B$. subtilis $s f p^{+} s w r A$ involves distinct stages, we anticipated that this should reflect differential expression of swarming genes. The major objective in this study was therefore to examine whether the development of dendrites was accompanied by spatiotemporal changes in gene expression and the appearance of distinctive cell types, with the primary focus on the hag gene (encoding flagellin). In addition, we hoped to define better the properties of swarmers, which so far are poorly characterized in B. subtilis. By measuring the pattern of expression from the hag promoter of an ectopic copy of a hag-gfp fusion, we were able to identify three distinct subpopulations of cells that differ in the level of hag expression: (i) long chains close to the edge of the MC with no detectable expression of hag, (ii) largely non-mobile cells in dendrite stems, with intermediate levels of hag expression; and (iii) a unimodal population of highly mobile cells, with hyper-expression of hag and other distinctive characteristics. These cells are first detected in pre-dendrite buds before forming the extreme $1 \mathrm{~mm}$ at the tip of elongating 
dendrites. Finally, we discuss the relative roles of the different cell types in the development of the swarm as dendrites elongate, with the high population density at dendrite tips playing a crucial role in the observed collective movement of the specialized swarmers.

\section{METHODS}

Strains and growth conditions. Bacterial strains used in this study are listed in Table 1. Details of strain construction in this study are shown in the Supplementary Methods. Bacteria were grown with aeration at $37{ }^{\circ} \mathrm{C}$ in synthetic $\mathrm{B}$ medium, composed of (final concentrations): $15 \mathrm{mM}\left(\mathrm{NH}_{4}\right)_{2} \mathrm{SO}_{4}, 8 \mathrm{mM} \mathrm{MgSO}_{4} \cdot 7 \mathrm{H}_{2} \mathrm{O}, 27 \mathrm{mM} \mathrm{KCl}, 7 \mathrm{mM}$ sodium citrate. $2 \mathrm{H}_{2} \mathrm{O}, 50 \mathrm{mM}$ Tris/ $\mathrm{HCl}, \mathrm{pH} 7.5,2 \mathrm{mM} \mathrm{CaCl}_{2} .2 \mathrm{H}_{2} \mathrm{O}, 1 \mu \mathrm{M}$ $\mathrm{FeSO}_{4} .7 \mathrm{H}_{2} \mathrm{O}, 10 \mu \mathrm{M} \quad \mathrm{MnSO}_{4} .4 \mathrm{H}_{2} \mathrm{O}, 0.6 \mathrm{mM} \quad \mathrm{KH}_{2} \mathrm{PO}_{4}, 4.5 \mathrm{mM}$ glutamic acid, $860 \mu \mathrm{M}$ lysine, $784 \mu \mathrm{M}$ tryptophan and $0.5 \%$ glucose (Antelmann et al., 1997). For the thr auxotrophs, both liquid and solid media were always supplemented with $1 \mathrm{mM}$ threonine. Antibiotics were added to plates at the following final concentrations: chloramphenicol, $5 \mu \mathrm{g} \mathrm{ml}^{-1}$; spectinomycin, $100 \mu \mathrm{g} \mathrm{ml}^{-1}$; erythromycin, $1 \mu \mathrm{g} \mathrm{ml}^{-1}$; lyncomycin, $12.5 \mu \mathrm{g} \mathrm{ml}^{-1}$.

Conditions for dendritic swarming experiments. For swarming on B medium, $9 \mathrm{~cm}$ swarm plates containing $25 \mathrm{ml}$ medium $(0.7 \%$ Bacto agar) were prepared $1 \mathrm{~h}$ before inoculation and dried with lids open for $5 \mathrm{~min}$ in a laminar flow hood. Plates could be dried for up to 15 min without affecting initial swarming behaviour. However, the longer periods of drying could result in the arrest of swarming, particularly in the laboratory strain, before reaching the edge of the plates, which normally took around 20-24 h. Cultures for inoculation were prepared in $10 \mathrm{ml} \mathrm{B}$ medium inoculated from a single colony on an LB agar plate and shaken overnight at $37^{\circ} \mathrm{C}$. The culture was diluted to $\mathrm{OD}_{570} \sim 0.1$ and grown at $37{ }^{\circ} \mathrm{C}$ to $\mathrm{OD}_{570} \sim 0.2$. This procedure was repeated twice and finally the culture was grown to $\mathrm{T}_{4}$ (4 $\mathrm{h}$ after the transition from exponential growth). The culture was diluted, and $10^{4}$ bacteria $(2 \mu \mathrm{l})$ were placed at the centre of a swarm plate and incubated at $30{ }^{\circ} \mathrm{C}$ (usually at a relative humidity of $70 \%$ ) for the times indicated below, or until the dendrites were approximately $1.5 \mathrm{~cm}$ in length $(\sim 16 \mathrm{~h})$. It was important to pay careful attention to the level of humidity in order to obtain robust, sustained swarming on B medium. In order to achieve this, we used an incubator that allowed precise control of temperature and humidity (Climacell 111). This protocol then ensured reproducible timing of the initiation of migration and pattern formation, but avoided any residual free water on the agar surface. Thus, a drop of water placed on these swarm plates did not spread (Banaha et al., 2009). Note that about $11 \mathrm{~h}$ of growth of the central MC occurred before eight to 12 monolayered primary dendrites radiated outwards from the edge of the MC at a constant speed of approximately $3.5 \mathrm{~mm} \mathrm{~h}^{-1}\left(1 \mu \mathrm{m} \mathrm{s}^{-1}\right)$ at $30{ }^{\circ} \mathrm{C}$ (Julkowska et al., 2004).

Images of swarm plates were taken with an Epson 1600 Pro scanner at $300 \mathrm{dpi}$, or where otherwise indicated at $1200 \mathrm{dpi}$.

Isolation of an swrA ${ }^{+}$revertant of strain $168 \mathbf{s f p}^{+}$. Swarm plates of strain $168 s f p^{+} s w r A$ (OMG 930) were prepared as above and incubated at $30-40 \%$ humidity. A swarm plate after $24 \mathrm{~h}$, showing some dendritic migration but prematurely arrested after approximately $1.5-2 \mathrm{~cm}$, was left at room temperature for 3 days at about $30 \%$ humidity. From the additional dendrites that finally arose from the edge of the arrested zone, some cells were removed and purified to single colonies, and the DNA was sequenced, as indicated below, to identify an $s w r A^{+}$revertant, SSB 2026.

Imaging and single-cell analysis: stereomicroscopy, phasecontrast and fluorescence microscopy. Cells at magnification $\times 150$ were examined in situ with a stereomicroscope (Zeiss Lumar), or with different objectives appropriate to a phase-contrast/fluor-

Table 1. Strains and plasmids used in this study

All the OMG strains (and SSB 2019, 2026) were derived from the laboratory strain $168 \operatorname{trp} C 2 s w r A$, which was restored to $s f p^{+}$by insertion into amyE or into thrC. OMG 991 is derived from the non-domesticated wild-type strain 3610 .

\begin{tabular}{|c|c|c|}
\hline Strain or plasmid & Genotype & Reference, source or construction \\
\hline \multicolumn{3}{|l|}{ Strains } \\
\hline 3610 & Natural isolate & Bacillus Genetic Stock Center collection \\
\hline 168 & $\operatorname{trpC2} s w r A s f p$ & European B. subtilis Genome Consortium \\
\hline OMG 900 & $\operatorname{trpC2} s w r A$ amyE::sfp ${ }^{+}$cat & Julkowska et al. (2005) \\
\hline OMG 930 & $\operatorname{trpC2} s w r A$ thrC:: sfp ${ }^{+} \mathrm{erm}$ & This work \\
\hline SSB 2026 & $\operatorname{trpC2} s w r A^{+}$thrC::sfp ${ }^{+}$erm & This work \\
\hline OMG 954 & $\operatorname{trpC2}$ swrA thrC::sfp erm $\Delta$ hag:: cat & Hamze et al. (2009) \\
\hline OMG 982 & $\operatorname{trpC2} s w r A$ thrC::sfp erm $\mathrm{P}_{R \lambda}-g f p m u t 3 s p c$ & This work \\
\hline OMG 984 & $\operatorname{trpC2}$ swrA thrC::sfp ${ }^{+}$erm amyE:: $\mathrm{P}_{\text {comA }}-g f p m u t 3 s p c$ & This work \\
\hline OMG $991(3610)$ & amyE:: $\mathrm{P}_{\text {hag }}-g f p m u t 3 s p c$ & This work \\
\hline OMG 992 & $\operatorname{trpC2} s w r A$ thrC::sfp ${ }^{+}$erm amyE:: $\mathrm{P}_{\text {hag }}-$ gfpmut3 spc & This work \\
\hline SSB 2019 & $\operatorname{trpC} 2$ swrA thrC::sfp$p^{+}$erm amyE:: $P_{e p s}-y f p$ spc & $\begin{array}{l}\left.\text { Derived from strain HV1046 (168 amyE:: } P_{e p s}-y f p s p c\right) \text {, a gift } \\
\text { from H. Vlamakis and R. Kolter }\end{array}$ \\
\hline \multicolumn{3}{|l|}{ Plasmids } \\
\hline pOMG 808 & PDG 1663 thrC::sfp & $\begin{array}{l}\text { This work; derived from pDG } 1663 \text { (Guérout-Fleury et al., } \\
\text { 1996) with } s f p \text { from pSV } s f p \text { (Nakano et al., 1992) }\end{array}$ \\
\hline pOMG 810 & PDL30 amyE: :gfpmut3-ter & This work; derived from pDL30 (Lynch et al., 2001) \\
\hline pOMG 812 & PDL30 amyE: $: \mathrm{P}_{\text {comA }}-g f p m u t 3-t e r$ & This work \\
\hline pOMG 816 & PDL30 amyE: : $\mathrm{P}_{\text {hag }}-$ gfpmut3-ter & This work \\
\hline pOMG 829 & PDL30 amyE:: $\mathrm{P}_{R \lambda}-g f p m u t 3-$ ter & This work \\
\hline
\end{tabular}


escence microscope (Zeiss AxioImager M1). Both microscopes were fitted with an AxioCam camera (Zeiss). In the Lumar instrument, GFP was excited at $450-490 \mathrm{~nm}$ and the fluorescence collected in the range 500-550 nm (filter set $38 \mathrm{HE}$ eGFP, Zeiss). In the fluorescence microscope, excitation wavelengths were $450-490 \mathrm{~nm}$ and emission wavelengths were 515-565 nm (filter set 10, Zeiss). A range of lowmagnification air objectives $(\times 1.25,5,20$ and 40$)$ were used initially to establish the perspective of images before selecting an appropriate field for analysis at high magnification. This was carried out as required with a $\times 63$ air or a $\times 100$ oil objective (numerical aperture $=1.3$ ). For the latter, regions of dendrites were observed with a microscope coverslip placed gently over the required portion of the swarm. This ensured minimal disturbance of the sample with the displacement at most of only a few cells from the edge of a dendrite.

To measure relative levels of fluorescence intensity in monolayered images resulting from $\mathrm{P}_{h a g}-g f p$ expression along the dendrite (semiquantitative analysis), images were captured using AxioVision software (release 4.6.3) and false-coloured. ImageJ software (Abramoff et al., 2004) was then used to calculate and format relative fluorescence intensities. It is important to note that for a highly expressed gene such as hag, swarms examined in the stereomicroscope were inoculated with $50 \%$ of cells expressing hag-gfp and $50 \%$ of the otherwise identical strain not expressing hag-gfp. At the low magnification employed with the stereomicroscope, this avoids any overlap of fluorescence signals from neighbouring cells, especially where a strong promoter is involved and in high population density regions, giving high fluorescence intensities that might be attributed spuriously to single cells by the software.

For the quantitative analysis of $\mathrm{P}_{h a g}-g f p$ expression along the dendrite with the microscope, images were captured using AxioVision software (release 4.6.3), false-coloured, and analysed with background subtraction, using AutoMeasure associated with the AxioVision software. The results were expressed in three ways: at the single-cell level (scatter plot), as fluorescence intensity per unit surface area (see Fig. 4b), as the mean fluorescence intensity of an entire field of cells (Fig. 4c), or as the fluorescence distribution within the population (Figs 5 and 6), where the single-cell dataset was fractionated to identify the number of cells in successive increments of 100 or 200 fluorescence units, as indicated below. The experiments, repeated three times, with one dendrite analysed from three different swarms, gave very similar results. For all quantitative single-cell measurements, between 500 and 900 cells per field were measured. Control experiments, in which cells were scraped from dendrites and dispersed at low density in buffer for fluorescence measurements, confirmed the existence of a gradient along dendrites, with tip cells hyper-expressing hag-gfp. Other control experiments also demonstrated that replicate fields in the same region in dendrites gave very similar results. This supports the notion that the dendrite population, except at the tips, is stable, with relatively little mixing, and maintains a constant population density.

\footnotetext{
Measurement of population density and length distribution along dendrites. For measuring the population density when dendrites were approximately 1 or $1.5 \mathrm{~cm}$ and still monolayered, cells were examined in situ by an AxioImager M1 microscope (Zeiss), using a $\times 40$ Neofluar objective. Images were captured using AxioVision software (release 4.6.3), and the population density was calculated using ImageJ software. The results were confirmed manually, with at least 3000 cells counted in duplicate or triplicate fields. Note that cells containing a clear septum were counted as two cells. As controls, several replicate fields sampled in close proximity were shown to give virtually identical counts. In order to obtain sharp images of otherwise hyper-mobile cells in situ in the tip region, swarms were placed under the microscope without covers for 5 min to reduce mobility.
}

DNA sequence analysis. Samples were transferred by toothpick from different locations (MC, base and tip of dendrites) of 3-4 cm diameter swarms on B medium plates of strain $168 s p^{+} s w r A$ directly onto $50 \mu \mathrm{l}$ of the complete PCR mixture (containing KOD polymerase, Novagen). The entire $s w r A$ gene and flanking regions $(1.8 \mathrm{~kb})$ were amplified (25 cycles) with oligonucleotides HP1433 (5'-ATATCTCGAGCGTACCCTGTCAATGTGATTACG-3') and HP1436 (5'-ATGTACTAGTCTTCAGTGATAATCAGCAAACCTAG- $3^{\prime}$ ). The amplified product was then purified (NucleoSpin Plasmid kit, Macherey-Nagel) and sequenced. Three experiments were carried out on different days, and in each case a dendrite was sampled at the locations indicated in the text from each of three swarm plates. The potential swrA revertant cells picked from dendrites developing at room temperature and low humidity were purified to single colonies, sampled for PCR and sequenced as above. The wild-type swrA gene in the non-domesticated strain 3610 was sequenced from cultures grown in liquid B medium.

\section{RESULTS}

\section{Dendritic migration of the laboratory strain 168 $\operatorname{sfp}^{+}$requires swrA ${ }^{+}$at low but not at high humidity}

The non-domesticated strain of B. subtilis, 3610, showed robust dendritic migration on the synthetic $B$ medium over a wide range of humidity. The laboratory strain 168 , when restored to $s \mathrm{pp}^{+}$(necessary for surfactin production), formed very similar branched dendritic patterns at $70 \%$ humidity (Supplementary Fig. S1), but failed to migrate reproducibly at low humidity (Julkowska et al., 2004, 2005; Hamze et al., 2009). This surface migration, as we showed previously, absolutely requires flagella and a surfactant, surfactin (Supplementary Fig. S2), i.e. the classical requirements for swarming migration (Harshey, 2003). In fact, strain 168 carries a mutation in swrA (Kearns et al., 2004; Hamze et al., 2009) which has been shown to be required for swarming on LB (Kearns et al., 2004) and recently on the minimal B medium (Patrick \& Kearns, 2009). Those authors, however, used an experimental protocol quite different from that employed here, including very dry conditions. We confirmed (Supplementary Fig. S3) that $168 s f p^{+} s w r A$ (OMG 930) failed to migrate or that migration arrested prematurely at $30-40 \%$ humidity.

In order to address further the question of the role of $s w r A$ in dendritic migration, we isolated an $s w r A^{+}$revertant of strain $168 \mathrm{sfp}^{+}$under strong selective conditions, i.e. extensive incubation around $30 \%$ humidity (see Methods). The migratory behaviour of this revertant strain, $168 s \mathrm{fp}^{+}$ $s w r A^{+}$(SSB 2026), was compared at both 30-40 and $70 \%$ humidity with that of the parental $168 s f p^{+} s w r A$ strain. Fig. 1 shows that the $s w r A$ mutant, as expected, failed to migrate at low humidity, while the revertant migrated robustly, further evidence that swrA is required for migration at low but not at high humidity. At $70 \%$ humidity, the initiation of dendritic migration is normally preceded by the appearance of the surfactin zone just before the emergence of pre-dendrite buds at around $11 \mathrm{~h}$ post-inoculation. For both the $s w r A$ and the $s w r A^{+}$strain, surfactin production and dendrite emergence were 
(a)

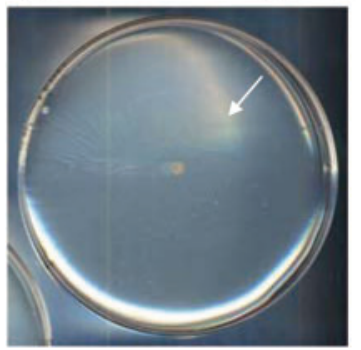

$168 s f p^{+} s w r A 22 \mathrm{~h}$

(b)

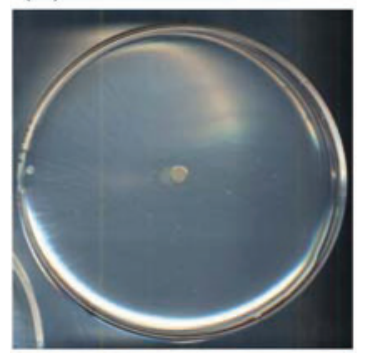

$168 \mathrm{sfp}^{+} \mathrm{swrA} 40 \mathrm{~h}$

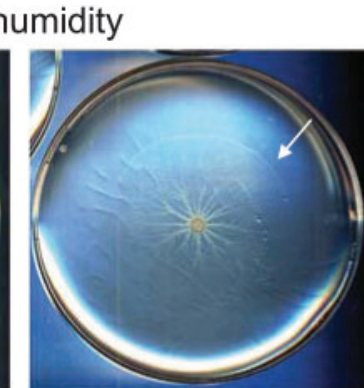

$168 s f p^{+} s w r A^{+} 22 \mathrm{~h}$

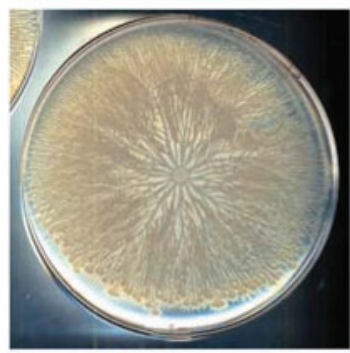

$168 s f p^{+} s w r A^{+} 40 \mathrm{~h}$

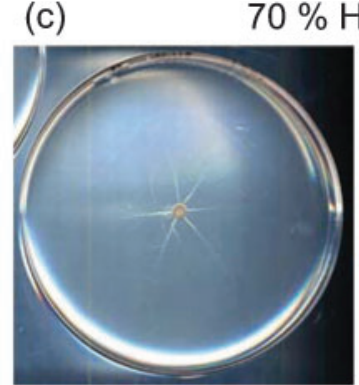

$168 s f p^{+} s w r A 22 \mathrm{~h}$

(d)

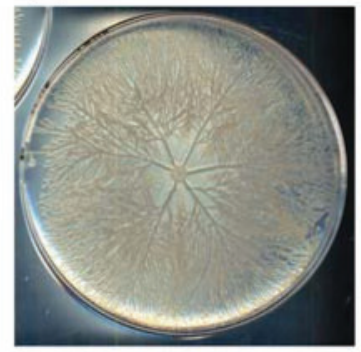

$168 s f p^{+} s w r A 40 \mathrm{~h}$

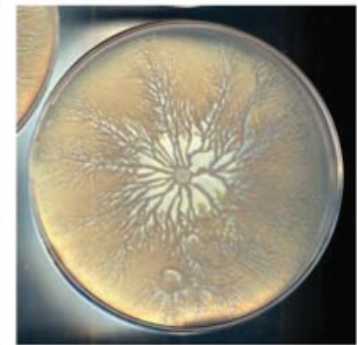

$168 \mathrm{sfp}^{+} \mathrm{swrA}^{+} 40 \mathrm{~h}$

Fig. 1. Dendritic migration of strain $168 \mathrm{sfp}^{+}$requires $s w r A^{+}$at low but not at high humidity. B medium swarm plates $(0.7 \%$ agar) were inoculated at the centre with $10^{4}$ early stationary phase $\left(\mathrm{T}_{4}\right)$ cells of strains $168 \mathrm{sfp}^{+} \mathrm{swrA}_{\text {(OMG } 930) \text { or } 168 \mathrm{sfp}}{ }^{+}$ $s w r A^{+}$(SSB 2026). For details of the preparation of swarm plates and the inoculum, see Methods. Plates were incubated at $30{ }^{\circ} \mathrm{C}$ and $30-40 \%(\mathrm{a}, \mathrm{b})$ or $70 \%$ relative humidity $(\mathrm{c}, \mathrm{d})$. Images were obtained after $22 \mathrm{~h}(\mathrm{a}, \mathrm{c})$ and $40 \mathrm{~h}$ (b, d) by scanning (see Methods). Arrows in (a) and (c) indicate the limit of the expanding surfactin zone, approximately $2 \mathrm{~mm}$ ahead of the advancing dendrite tips, not visible in these photographs. At $70 \%$ humidity, the number of initial dendrites in the mutant tended to be variable in the absence of swrA (compare with Supplementary Figs S1 and S2).

observed at approximately the same time (data not shown). Moreover, development was still very similar at $22 \mathrm{~h}$ in the two strains (Fig. 1a, c). Finally, at 40 h, both strains showed overall similar robust patterns of migration (Fig. 1b, d). We note that in this experiment, the number of initial dendrites at $70 \%$ humidity was lower in the swrA strain than in the $s w r A^{+}$strain. However, this varied in different experiments, and, as shown in Supplementary Fig. S1, in some experiments the $s w r A$ strain produced a much higher number of dendrites.

Next, we analysed the status of the swrA gene during expansion of the community of $168 s \mathrm{fp}^{+}$swrA (OMG 930) at $70 \%$ humidity. The tips of $1.5-2 \mathrm{~cm}$ dendrites were sampled from a total of nine dendrites from three different plates in separate experiments, and analysed by PCR and sequencing of the entire swrA gene (see Methods). Two additional samples were taken from MCs and from the base of two dendrites from different plates, and analysed similarly. As shown in Supplementary Fig. S4, the wild-type $s w r A^{+}$gene was not detected in any of the samples and the frameshift mutation was still present in the $168 \mathrm{sfp} \mathrm{p}^{+}$cells, i.e. an insertion of a single base pair, AT, at codon 12, in a run of eight Ts in the $s w r A$ gene. This insertion is not found in the non-domesticated strain 3610 (also shown in Supplementary Fig. S4). Thus, in our hands, robust dendritic migration of this strain is not accompanied by reversion of the swrA mutation, confirming that at $70 \%$ humidity the swrA gene is dispensable.

\section{Long septated chains of cells not expressing hag appear early and accumulate at the edge of the MC on swarm plates incubated at $70 \%$ humidity}

Following inoculation of swarm plates with strain $168 \mathrm{sfp}{ }^{+}$ swrA, cells grew for $10-11 \mathrm{~h}$ to form the MC, before the appearance of the outward-expanding zone of surfactin. We have observed in both the domesticated and nondomesticated strain (168 sfp ${ }^{+} s w r A$ and 3610 , respectively) that this early growth of the $\mathrm{MC}$ is accompanied by the appearance of long cell forms on both LB and B medium plates (Julkowska et al., 2004; Hamze et al., 2009). We now show that staining of such cells in situ in the MC with a membrane stain (see Supplementary Methods) shows that the long cell forms are septated (Supplementary Fig. S5). These cells therefore appear identical to B. subtilis chains that previously were first identified as a distinct 
subpopulation present in liquid cultures. In such cells, the production and activity of the transcription factor $\sigma^{\mathrm{D}}$ is switched off, resulting in the absence of hag expression (flagellin) and of the expression of certain autolysins encoded by lytABC (Kearns \& Losick, 2005; Chen et al., 2009; Cozy \& Kearns, 2010).

To examine hag expression in the chain forms, a derivative of $168 s \mathrm{fp}^{+}$swrA (OMG 992) was constructed that carries, in addition to the normal hag gene, a $\mathrm{P}_{\text {hag }}-g f p$ fusion inserted into the amyE locus (see Supplementary Methods). Examination of cells during the early stages of growth of the MC and subsequent migration confirmed that the long forms did not fluoresce, i.e. they did not express hag. Thus, Fig. 2(a, b) shows at $10 \mathrm{~h}$ postinoculation the appearance of microcolonies and elongated non-fluorescent cells already present randomly distributed in the MC. By $12 \mathrm{~h}$ the long cells formed an extensive network, in particular at the edge of the MC (Fig. 2d). We note, however, that the chaining state in the swarm community is transient and has disappeared in older multilayered dendrites. Thus, when viewed at $24 \mathrm{~h}$, the great majority of cells in the MC and along dendrites were of normal length and expressed hag (data not shown). Finally, we showed that the long forms expressed high levels of eps (exopolysaccharide production), with very low or background levels of expression in distal regions of dendrites, as revealed using an eps-gfp fusion in strain 168 $s f p^{+}$(Supplementary Fig. S6).

\section{Single-cell quantitative analysis of hag-gfp expression in situ reveals a gradient along dendrites, increasing sharply at the tips}

In anticipation that the regulation of flagella production is coupled in some way to the mechanism of elongation/ migration of dendrites, we examined the spatial expression of hag, using $168 s f p^{+} s w r A$ carrying the $\mathrm{P}_{\text {hag }}-g f p$ fusion (OMG 992). Dendritic migration from the multilayered MC was allowed to develop until dendrites extended up to $1.5 \mathrm{~cm}$. This occurs essentially as a monolayer of cells, ideal for in situ analysis without disturbing the cells. For greater convenience and rapid acquisition of data, the initial experiments employed a stereomicroscope at a relatively low magnification $(\times 150)$. In this way, semiquantitative measurements of the relative fluorescence intensity of cells could be generated rapidly from images taken in situ. Several images were obtained along different dendrites ( 1 or $1.5 \mathrm{~cm}$ ) and fluorescence levels were analysed (see Methods). Typical results, shown in Fig. 3, indicated an apparent gradient of expression of hag-gfp along the dendrites, with a particularly marked increase towards the tip (Fig. 3, a1, a2, b). Similar results were consistently obtained with different dendrites on the same plate or with dendrites from swarms on different days. Moreover, a similar gradient of hag expression from a maximum at the tip was detected, as shown in Supplementary Fig. S7, for the non-domesticated strain 3610 $\mathrm{P}_{\text {hag }}-g f p$ (OMG 991; see Supplementary Methods for
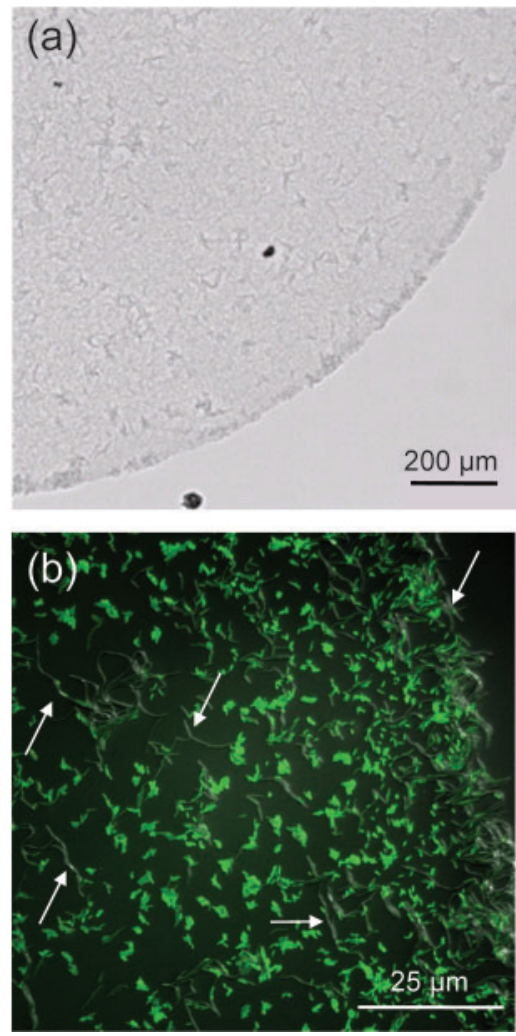

Fig. 2. Long chains that accumulate early at the edge of the $\mathrm{MC}$ do not express hag. $\mathrm{B}$ medium swarm plates were prepared and inoculated, as in Fig. 1, in this case with strain 168 sfp $^{+} P_{\text {hag }}-g f p$ (OMG 992). (a) Bright-field view of the MC in situ $(10 \mathrm{~h})$ with microcolonies beginning to develop. (b) Image taken in situ at $10 \mathrm{~h}$ in the fluorescence microscope at higher magnification, showing normal-sized fluorescent cells and longer, non-fluorescent cells (examples arrowed), already appearing within the MC. (c) At 11-12 h, small monolayered buds emerge from the edge of the $\mathrm{MC}$ and large numbers of the long septated forms are seen accumulating in the region indicated between the arrows. (d) Fluorescent image at higher magnification of the region between the arrows in (c), with the long forms clearly nonfluorescent. Note the clear demarcation of normal-sized cells, which form a narrow zone at the extreme edge of the MC, from the network of long-chain forms, indicating clonal development of distinct cell types in close proximity. 


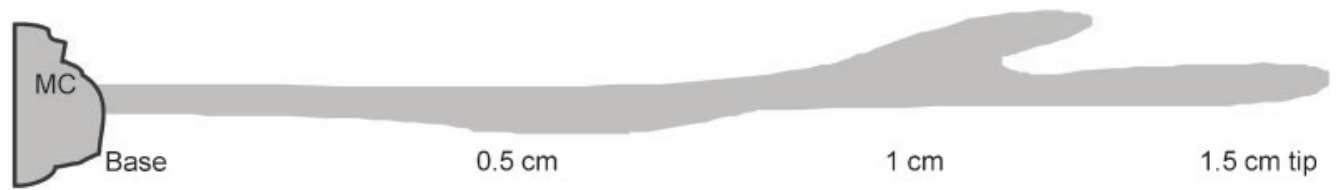

(a1)
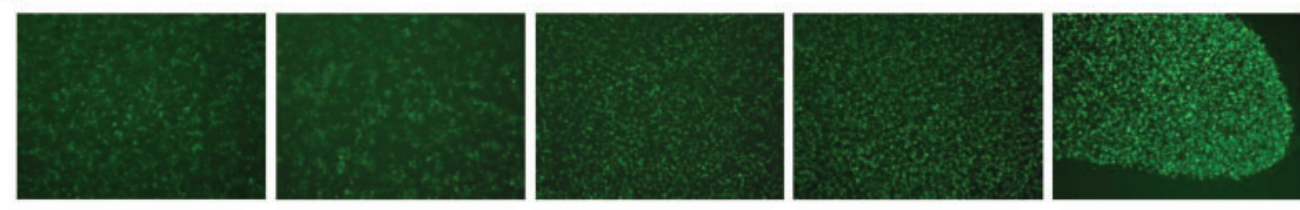

(a2)

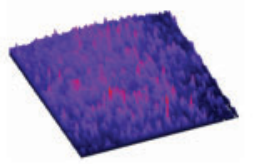

MC

(b)

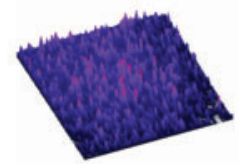

(c)

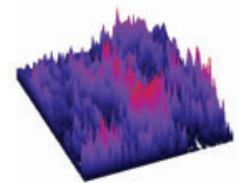

(d)

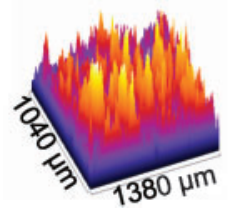

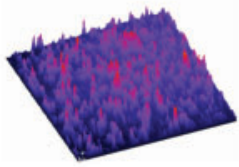

Base
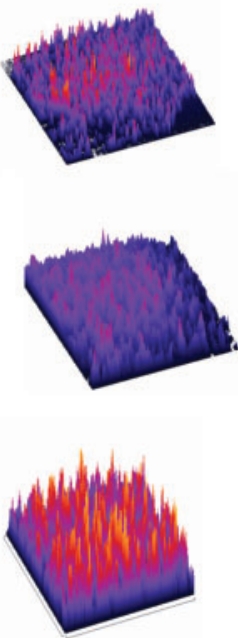

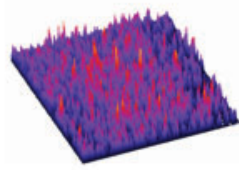

$0.5 \mathrm{~cm}$
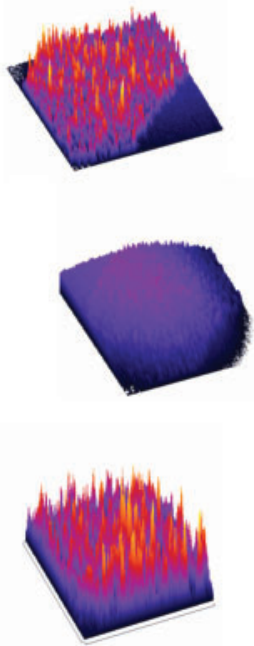

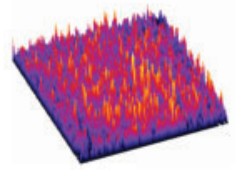

$1 \mathrm{~cm}$
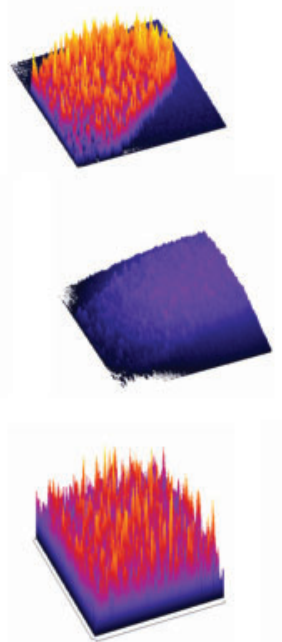

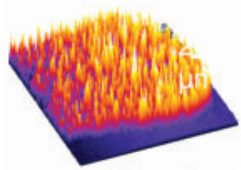

$1.5 \mathrm{~cm}$ tip

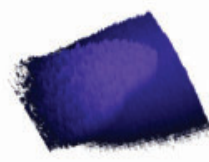

$\mathrm{P}_{\text {comA }}$ gfp $^{-g f p}$

$\mathrm{P}_{h a g}-g f p$

(n)
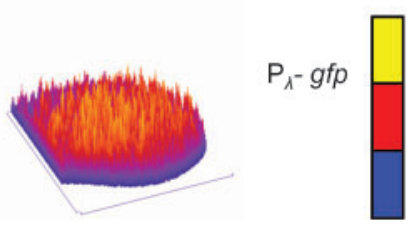

Fig. 3. Semiquantitative analysis of hag-gfp fluorescence in situ along dendrites shows a gradient of expression, maximal at the tip. B medium swarm plates and cells were prepared as in Fig. 1, and plates were inoculated with the strains indicated below. Plates were incubated at $30{ }^{\circ} \mathrm{C}$ for approximately $16 \mathrm{~h}$ (producing $1.5 \mathrm{~cm}$ dendrites) or $14.5 \mathrm{~h}(1 \mathrm{~cm}$ dendrites). Images were taken in situ at different positions along a monolayered dendrite, as indicated in the cartoon at the top. (a1) Raw fluorescence images for a $1.5 \mathrm{~cm}$ dendrite after inoculation with $50 \% 168 \mathrm{sfp}^{+} \mathrm{P}_{\text {hag }}-g f p$ cells and $50 \% 168$ sfp ${ }^{+}$cells with no gfp fusion (OMG 992 and OMG 930, respectively). This avoids the overlap of fluorescence signals from neighbouring cells, and is necessary at the low magnification employed in the stereomicroscope when analysing highly expressed promoters. Note the apparently increased population density at the tip. (a2, b) Typical images of the hag-gfp swarms obtained in situ from a $1.5 \mathrm{~cm}$ and a $1 \mathrm{~cm}$ dendrite, respectively, analysed by ImageJ software (see Methods). The relative fluorescence intensity per cell is indicated by yellow maximum and blue minimum. (c) Expression along a dendrite after inoculation with a strain expressing comA-gfp (OMG 984). (d) Expression along a dendrite after inoculation with $50 \%$ OMG 982 expressing gfp from a constitutive $\lambda P_{R}$ promoter and $50 \%$ OMG 930. The dimensions of the stereomicroscope fields analysed are indicated to the left of (d).

construction). In contrast to hag-gfp, the expression of an artificial gene construct of $g f p$ inserted into the amyE locus and expressed from a modified (constitutive) E. coli $\lambda \mathrm{P}_{\mathrm{R}}$ promoter (see Supplementary Methods) displayed no obvious gradient along the dendrite (Fig. 3d). Another control experiment involved a strain expressing a $\operatorname{com} A-g f p$ fusion to monitor the expression of a gene involved in regulation of surfactin production. Interestingly, this construct also revealed a gradient of expression, although the complete reverse of hag, being minimal at dendrite tips
(Fig. 3c). These results all support the conclusion that the expression of hag varies to form a specific gradient along dendrites.

In order to confirm quantitatively the gradient of $h a g-g f p$ expression with strain $168 s f p^{+} s w r A$, we measured fluorescence intensity in single cells from a series of images taken in situ along dendrites at high magnification. In such images, the great majority of cells in the monolayer were clearly separable (Fig. 4a), and typical results for a $1.5 \mathrm{~cm}$ 
(a)

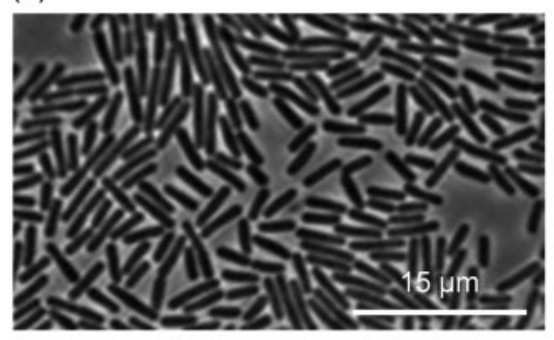

(b)

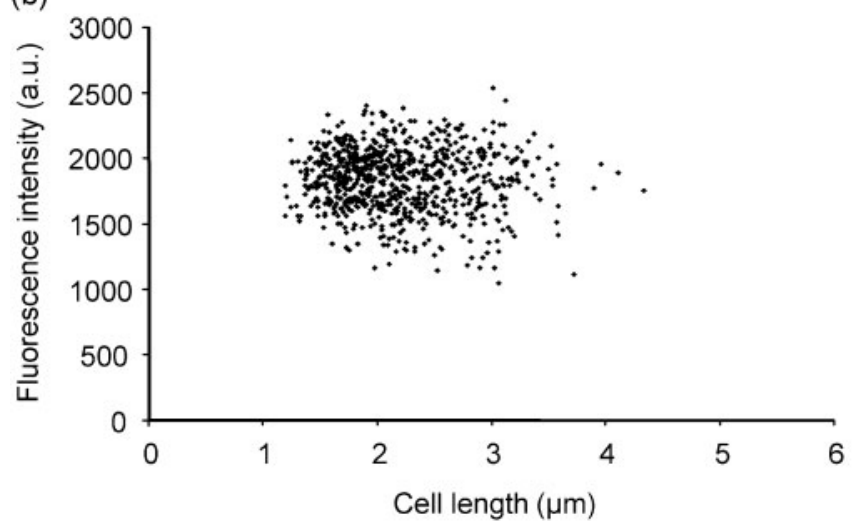

(c)

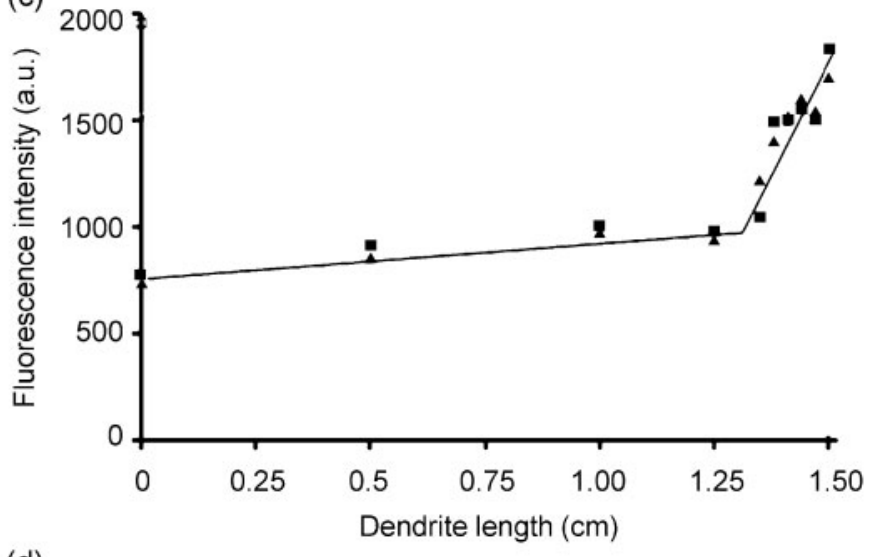

(d)

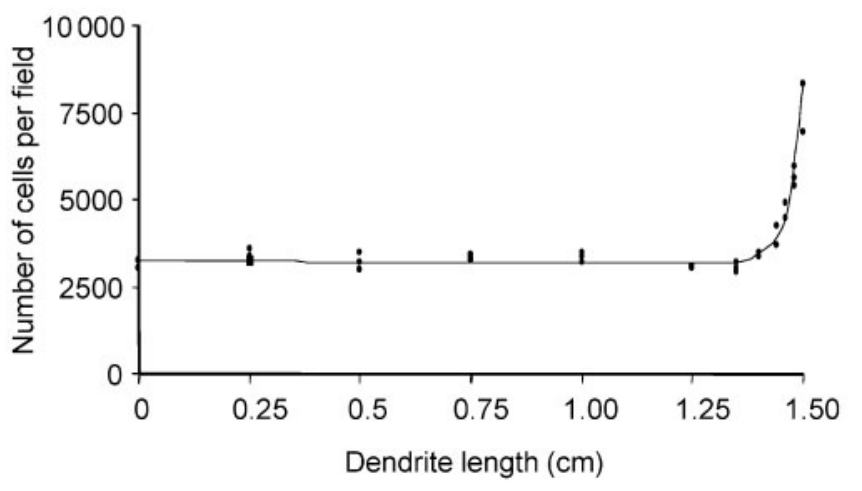

Fig. 4. Single-cell, quantitative analysis in situ along a dendrite reveals hyper-expression of $\mathrm{P}_{\text {hag }}$-gfp in dendrite tips overlapping a region of high population density. B medium swarm plates were prepared and inoculated as in Fig. 1, but with strain $168 \mathrm{sfp}^{+} P_{\text {hag }}$-gfp (OMG 992). Plates were incubated until dendrites reached $1.5 \mathrm{~cm}$ (16 h). (a) Typical microscope field of the monolayer of cells $(1.25 \mathrm{~cm}$ from the base in this example) obtained in situ with the fluorescence microscope $(\times 100$ objective). (b) Typical scatter plot of fluorescence intensity (a.u.) per unit surface area of cells versus cell length, in this case a field of cells in the tip region. (c) Mean fluorescence intensity values from images ( $\times 40$ objective) of 500-900 cells obtained along the dendrite and plotted against dendrite length. Two individual replicate fields analysed in the adjacent regions at a particular position of the dendrite are represented by different symbols. The mean fluorescence intensity for each field was then calculated. (d) Population density along a dendrite determined from images ( $\times 40$ objective) obtained in situ, counting at least 1000 cells in each of two adjacent fields at each position (see Methods).

dendrite, based on the analysis of 500-900 cells per field, are presented as a function of cell length in a scatter plot and in graphical form (Fig. $4 \mathrm{~b}$ and c, respectively). The results of such single-cell measurements of hag expression in situ (expressed as the mean fluorescence intensity in cells per unit surface area) confirmed the presence of a shallow gradient of increasing expression of hag- $g f p$, from the base to close to the tip of the dendrite. However, the mean fluorescence within the last $1-1.2 \mathrm{~mm}$ at the extremity of the dendrite rose rapidly, giving a 2.5 -fold increase compared with the base, with a maximum mean fluorescence intensity of 1850 arbitrary units (a.u.).

The results presented above, indicating sharply increased hag expression in dendrite tips, suggested the presence of hyper-flagellated cells. This was indeed confirmed by removal of cells from different positions along dendrites and examination by electron microscopy (see Methods). Cells taken from the tips of dendrites had around 24 flagella, while cells from the base of dendrites had around 10-12 flagella (Supplementary Fig. S8).

\section{A unimodal population expressing high levels of hag-gfp in dendrite tips overlaps a region of high population density of strain $168 \mathrm{sfp}^{+}$swrA}

The raw fluorescence intensity data for hag-gfp expression shown, for example, in Fig. 4(b) were also analysed with respect to the distribution of fluorescence levels amongst the population in different regions along a $1.5 \mathrm{~cm}$ dendrite. The results presented in Fig. 5 show a wide range of hag expression in the population at the base of dendrites with respect to fluorescence levels. However, analysis along the 
stem of the dendrite progressively revealed a more bimodal distribution. Finally, a unimodal population of cells with high levels of hag expression was detected within approximately the terminal $1.0 \mathrm{~mm}$ at the tip. Similar results were obtained from three independent swarms analysed on different days.

Microscope observations demonstrated that the cells in the extreme tip regions of dendrites were also characterized by their hyper-motility and apparent packing to a higher population density compared with the rest of the dendrite. This was confirmed by directly measuring the population density along $1.5 \mathrm{~cm}$ dendrites. Images were taken in situ in three dendrites from different swarms, with virtually identical results. Although the cells were distributed in the form of a loose irregular matrix along the stems of dendrites, the results in Fig. 4(d) show that the overall population density in the microscope fields was constant throughout most of the dendrite. This, together with the general immobility of these cells, also suggested that there was relatively little mixing within the dendrite stem. In contrast to the constant population density in the stem, the population density rose sharply within the terminal $1 \mathrm{~mm}$, overlapping the region occupied by the hyper-mobile, high hag-expressing cells. The possible relationship between population density and the mobility of these cells will be discussed below.

\section{A unimodal population of cells (swarmers) with hyper-expression of hag-gfp can already be detected in the 'pre-dendrite' buds}

The observed increased hag expression that was confined to the extreme tips of dendrites, as described above, raised the question of whether hag hyper-expression might be essential for initiation and maintenance of swarming per se, or whether upregulation was only triggered during elongation of dendrites. To address this question, we investigated the properties of the cells in 'pre-dendrite' buds.
As the first indication of dendrite formation, buds emerged from the edge of the $\mathrm{MC}$ at around $11 \mathrm{~h}$ post-inoculation (see Fig. 2c). In buds, as in dendrite tips, the cells were seen to be packed to a high density, which was reduced in the proximal region (Fig. 6c). Using strain $168 s f p^{+} s w r A$ carrying the $\mathrm{P}_{\text {hag }}-g f p$ fusion (OMG 992), a quantitative, single-cell analysis in situ was carried out from microscope images taken at different positions across an entire $1 \mathrm{~mm}$ pre-dendrite bud (Fig. 6a). This revealed high mean fluorescence intensities in all these cells, similar to that found in dendrite tips. Moreover, the distribution analysis of fluorescence intensity in the buds (Fig. 6b) also showed a unimodal population of cells, similar to that found in dendrite tips (compare with Fig. 5). Finally, we observed that the cells in the buds were also highly mobile (data not shown). We conclude that the cells in this subpopulation are required to lead the way out of the $\mathrm{MC}$, resulting in bud formation. These specialized hyper-mobile cells, which we designate swarmers, then spearhead the developing dendrites, moving, as we show below, in packs of aligned cells.

\section{B. subtilis swarmers move over swarm plates in a thin fluid film, and show coordinated movement of swirling and streaming packs}

Swarmers in P. mirabilis are long filamentous cells and are abundantly flagellated (Fraser \& Hughes, 1999), while their equivalents in E. coli and Salmonella (McCarter, 2010) are much less elongated, with only a moderate increase in flagella. Similarly, for B. subtilis on LB plates, cells at the swarm front are not filamentous (Kearns \& Losick, 2003; Julkowska et al., 2005). As shown in Fig. 7, a length distribution analysis from images taken along $1.5 \mathrm{~cm}$ dendrites (strain $168 s f p^{+} s w r A$ ) revealed a population at the base and along most of the stem of dendrites, with a length distributed around $2.5 \mu \mathrm{m}$. In contrast, at the tips, a large proportion of cells were smaller, with a mean length of around $2 \mu \mathrm{m}$, with a long tail of a distribution of longer cells similar to that found in the dendrite stem.

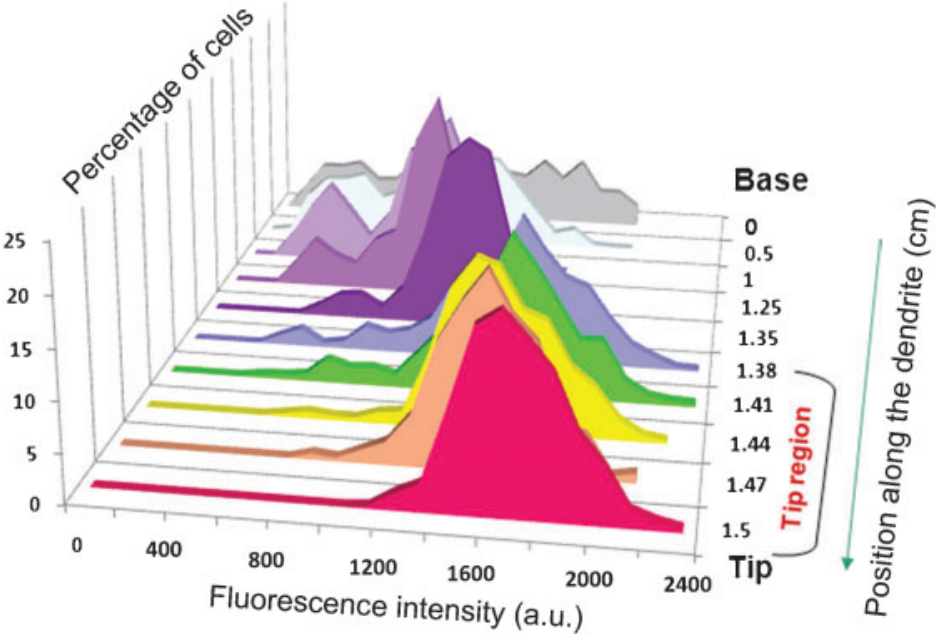

Fig. 5. A unimodal population of cells hyperexpressing maximum levels of $P_{\text {hag }}-g f p$ localizes to dendrite tips. B medium swarm plates were prepared and inoculated as in Fig. 1, in this case with strain $168 \mathrm{sfp}{ }^{+} P_{\text {hag }}-$ gfp (OMG 992). Plates were incubated for $16 \mathrm{~h}$, and single-cell measurement of fluorescence intensity (in a.u.) along a $1.5 \mathrm{~cm}$ dendrite in situ was carried out as in Fig. 4. The distribution of fluorescence intensity (increments of 100 a.u.) within the population was determined as described in Methods from images taken at different positions (indicated at the right). At least 1600 cells were measured for each position. 
(a)

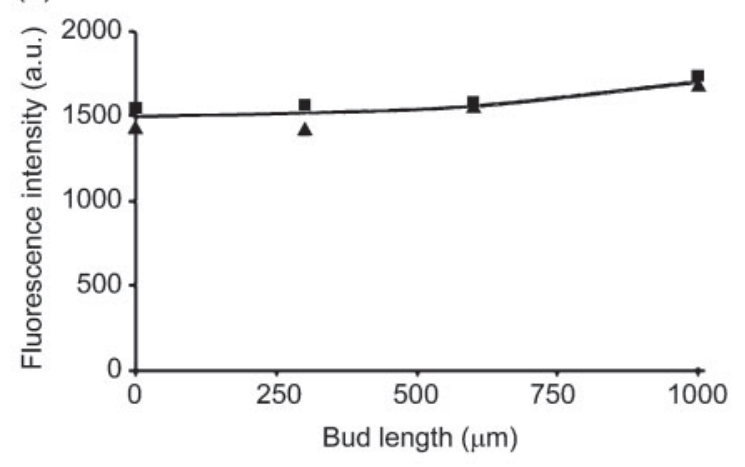

(b)

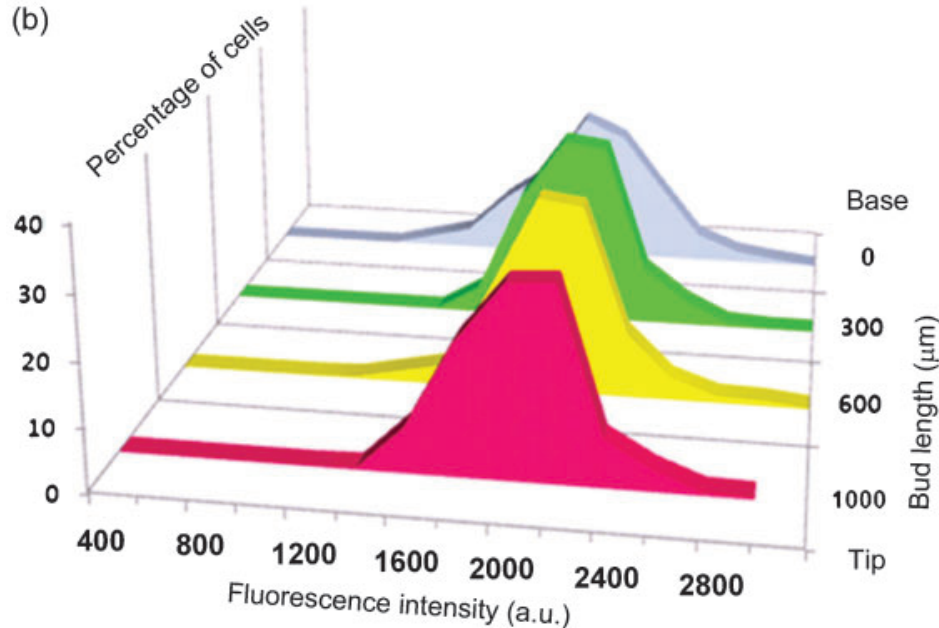

(c)

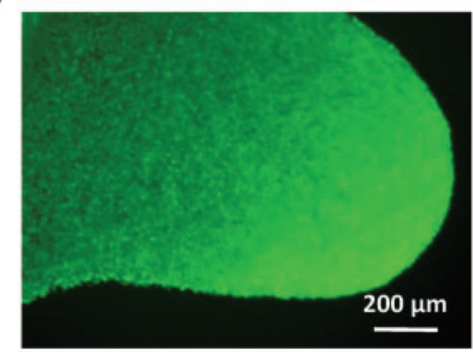

Fig. 6. Single-cell analysis in situ of $\mathrm{P}_{\text {hag }}-g f p$ expression across an emerging bud. $B$ medium swarm plates were prepared and inoculated as in Fig. 1, in this case with strain $168 \mathrm{sfp}^{+} P_{\text {hag }}{ }^{-}$ gfp (OMG 992). Plates were incubated for $11 \mathrm{~h}$ until emerging buds were seen at the edge of the MC. (a) Images were taken in the microscope $(\times 100$ objective $)$ at four different locations from base to tip. Duplicate images (different symbols) were obtained at each position (400-700 cells analysed per field). (b) Mean fluorescence intensity in single cells measured from an entire field, as described in Fig. 4, was determined as a function of bud length. Then the distribution of fluorescence intensity (fractionated in increments of 200 a.u.) in the population across the bud was derived from single-cell measurements. (c) Raw fluorescence image of a $1 \mathrm{~mm}$ bud (dotted line indicates the limit of the MC) taken in situ at low magnification, illustrating the typical closer packing of the cells towards the leading region of the bud.
Patrick \& Kearns (2009) inferred from their results that dendritic migration of the laboratory strain $168 s \mathrm{fp}^{+} \mathrm{swrA}$ at $70 \%$ humidity might be explained by excess water exposed on the surface on the agar in swarm plates, facilitating swimming rather than swarming. However, several lines of evidence clearly preclude this interpretation. For example, a drop of water placed on a correctly prepared B medium swarm plate does not spread, showing the absence of surface water. In contrast, on insufficiently dried plates we observed that the bacteria simply dispersed and that dendritic patterns did not form.

Importantly, we have emphasized previously (Julkowska et al., 2004, 2005; Hamze et al., 2009) that dendritic migration involves translocation of cells over the surface as a monolayer. Close inspection of the monolayer at high magnification showed that the bacteria were restricted to a single focal plane (see, for example, Supplementary Movie Files S1 and S2), demonstrating that they are confined to a thin (effectively 2D) film, considered to be a typical feature of swarming bacteria (Harshey, 2003; Darnton et al., 2010). Finally, when we examined the monolayer of $B$. subtilis cells $\left(168 s \mathrm{sp}^{+} \mathrm{swrA}\right)$ at the extreme $1 \mathrm{~mm}$ of dendrite tips, time-lapse filming revealed coordinated movements, very similar to those recently described for E. coli swarmers. Thus, as illustrated in Supplementary Movie Files S1 and S2 (14 frames s ${ }^{-1}$ ), the cells formed many short-lived rafts or packs composed of around three to eight aligned cells. As shown in Supplementary Movie File S3, when cells at dendrite tips were filmed at 40 frames s$^{-1}$, we saw highly mobile swirling packs and large streams of cells, behaviour resembling the 'acrobatics' shown by E. coli (Copeland et al., 2010; Darnton et al., 2010; Turner et al., 2010; McCarter, 2010). Such behaviour has been shown to be 

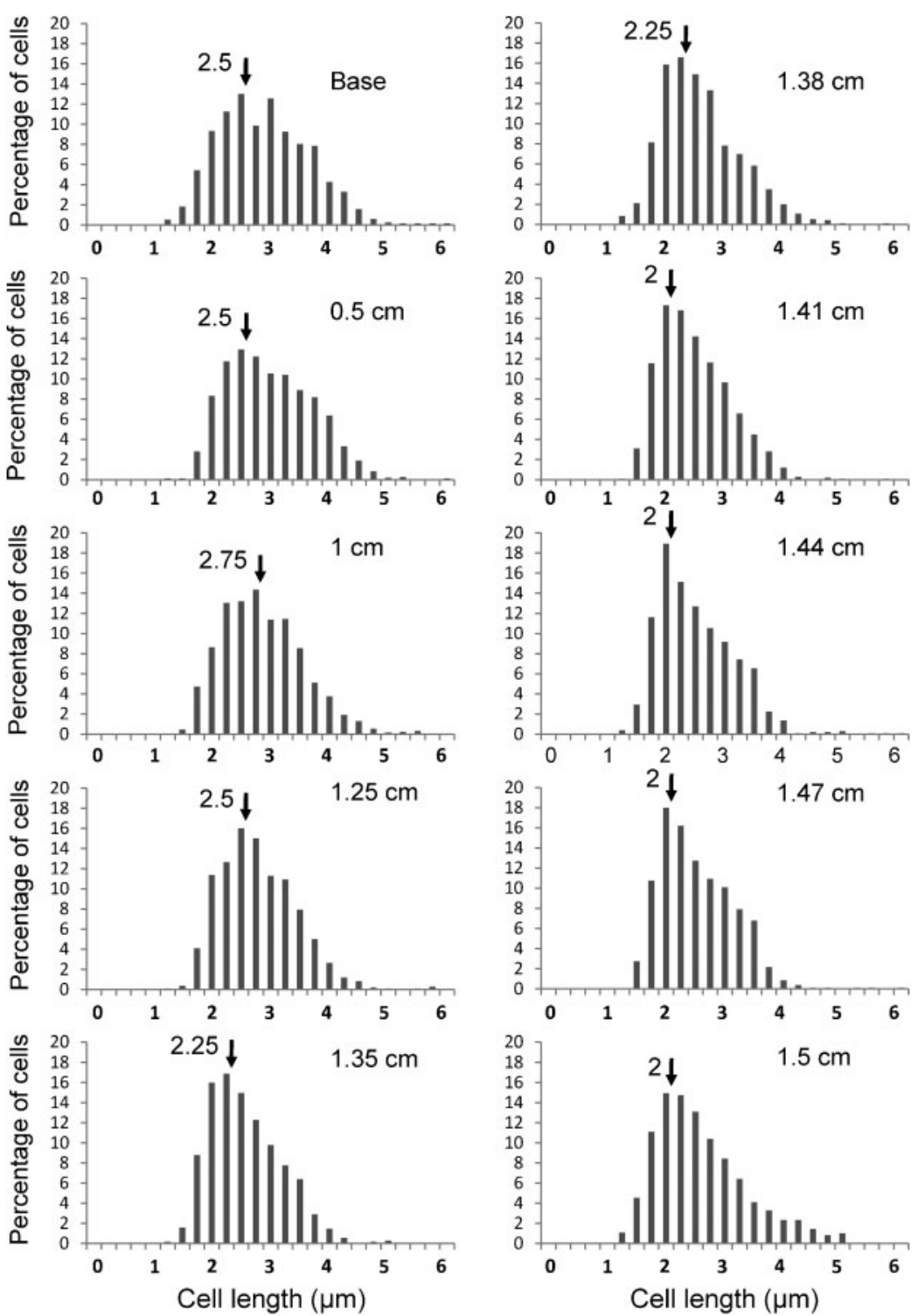

Fig. 7. Length distribution of cells along a $1.5 \mathrm{~cm}$ dendrite. $\mathrm{B}$ medium swarm plates were prepared and inoculated as in Fig. 1, but with strain $168 \mathrm{sfp}^{+} P_{\text {hag }}-g f p$ (OMG 992), and the plates were incubated until dendrites reached $1.5 \mathrm{~cm}$. The length distribution of the cells was determined at the different positions indicated along the dendrite from images taken in the microscope ( $\times 100$ objective), using the AxioVision software (see Methods). At least 2000 cells were measured for each position, and the data shown represent the percentage of cells with increasing cell length in successive $0.25 \mu \mathrm{m}$ increments. Similar results were also obtained with strain OMG 984. characteristic of bacteria suspended in a thin fluid film (Sokolov et al., 2007).

\section{DISCUSSION}

\section{Dendritic migration of $B$. subtilis $168 \mathrm{sfp}^{+}$swrA at high $(70 \%)$ humidity displays all the hallmarks of swarming}

The previous contradictory reports (Julkowska et al., 2004, 2005; Hamze et al., 2009; Patrick \& Kearns, 2009) on the ability of a laboratory strain of B. subtilis $168 s f p^{+} s w r A$ to swarm are resolved here with the finding that while swrA is required for robust migration at low humidity (also found by Patrick \& Kearns, 2009), this is not required at $70 \%$ humidity, as found previously (Hamze et al., 2009). Moreover, at $70 \%$ humidity, the time course of migration and subsequent pattern formation of both the swrA and $s w r A^{+}$forms of $168 s f p^{+}$were similar, and migration did not involve reversion to $s w r A^{+}$.

Early stages of dendritic migration involve the extension of stems and tips as a monolayer of cells, apparently within a thin fluid film, with movement limited to two dimensions. On the other hand, the amphiphilic surfactin molecules, as they spread ahead of the advancing cells, presumably partition at the air-agar interface. Consequently, we suggest that the cells move over the surface in a thin layer of fluid beneath the surfactant. Indeed, this has recently been reported for E. coli swarmers (Zhang et al., 2010), although in that case the surfactant remains to be identified. We now also demonstrate (Supplementary Movie File S3) that $168 s f p^{+} s w r A$ cells in dendrite tips move collectively as swirling and streaming packs. This behaviour is very similar to that of the E. coli swarmers 
described in three recent studies, all employing 90-100\% humidity (Copeland et al., 2010; Darnton et al., 2010; Turner et al., 2010; and see review by McCarter, 2010, and movie files accessible therein). Thus, dendritic migration for strain $168 s f p^{+} s w r A$, which, in addition, we have shown is dependent on flagella and surfactin (Julkowska et al., 2005; Hamze et al., 2009), quite clearly shows all the generally accepted characteristics of swarming.

\section{Long-chain forms}

In this study, our major objective was to focus on the temporal and particularly the spatial regulation of hag expression in situ in the developing community of the laboratory strain $168 s f p^{+}$. For this we took advantage of the persisting monolayer of cells that occurs from early bud (pre-dendrite) formation to dendrites up to $1.5 \mathrm{~cm}$ long. As a result, as discussed below with respect to hag expression, we identified three distinct cell types, temporally and spatially separated.

The long-chain forms could already be detected at $10 \mathrm{~h}$, and accumulated in large numbers at the edge of the $\mathrm{MC}$ at around $12-16 \mathrm{~h}$ post-inoculation, as we have previously shown for the non-domesticated strain 3610 (Julkowska et al., 2004). These cells expressed high levels of eps (extracellular polysaccharide), but had no detectable hag expression. These chain forms appeared identical to the subpopulation of chaining cells in cultures of B. subtilis observed at the centre of swarms on rich medium (Kearns \& Losick, 2003, 2005; Julkowska et al., 2005). The origin of these cells has been shown in liquid cultures to be dependent upon a bistable switch (Kearns \& Losick, 2005; Cozy \& Kearns, 2010), which ultimately regulates the level of the transcription factor $\sigma^{\mathrm{D}}$, leading to repression of flagellar and autolysin genes in the chain forms. The SinI/SinR and Slr regulators also play a critical role in this switch, involving the upregulation of extracellular matrix production (Chu et al., 2006, 2008; Kobayashi, 2008; Chai et al., 2009; see also Chen et al., 2009), as we also found here. Since bundling of such chain forms constitutes an early step in biofilm formation (Branda et al., 2001; Kearns et al., 2005; Kobayashi, 2007), we assume therefore that such cells play a similar role in building the $\mathrm{MC}$ at the centre of the swarm community. However, we have not ruled out an additional role in the migration phase.

\section{Non-swarmers, apparently physically immobilized}

A rather heterogeneous population of cells was seen to constitute the great majority in dendrite stems. Further studies are required to establish the properties of these cells. However, in comparison with chain forms and swarmers, these cells differed with respect to length distribution and had intermediate levels of hag expression and correspondingly around 12 flagella, although they were nevertheless largely immobile. We suggest that this immobility is due to the fact that these cells, present at a relatively low density compared with tip cells, are 'clamped' by the high capillary forces prevailing in thin films. Thus, these cells, if physically removed from stems and resuspended in medium, become mobile. This appears to rule out a mechanism of immobilization due to the binding of EpsE to the flagellar motor (see also Supplementary Fig. S6), which occurs in $B$. subtilis biofilms (Blair et al., 2008). Interestingly, front-line cells at the extreme edge of tips were also normally static, but if individuals were reincorporated into the interior as the tip advanced, they immediately became mobile (Supplementary Movie Files S1-S3). Conversely, if mobile cells became incorporated into the front line of dendrite tips, they became immobile, but then regained mobility if reincorporated as dendrites advanced. All these findings argue strongly for a physical explanation of the observed immobility of cells in dendrite stems and at the extreme edge of tips, where capillary forces should be maximal. In contrast, in the interior of dendrite tips, the closely packed hyper-flagellated swarmers, benefiting from overlapping menisci, could be subject to reduced capillary forces and therefore able to remain mobile.

\section{Specialized swarmers}

A third, spatially distinct cell type in the swarm community in strain $168 s f p^{+} s w r A$, detected later than the chain forms, was identified as a unimodal, monolayered population at the extreme $1 \mathrm{~mm}$ of tips, and was present during dendrite elongation up to at least $1.5 \mathrm{~cm}$ (Fig. 5). These highly mobile cells packed to a high population density and displayed hyper-expression of the hag gene, with, conversely, minimal levels of comA and eps expression compared with cells in the base of the dendrites. Importantly, an apparently identical subpopulation of highly mobile cells, expressing high levels of hag, was identified in pre-dendrite buds (Fig. 6). Therefore, we conclude that these cells, which we designate as swarmers, first spearhead the emerging buds and then constitute the tips of the elongating dendrites. However, we have no indication as yet of the mechanism that triggers and then maintains, over several generations, the characteristic properties of these swarmers.

Differentiated swarmers of $P$. mirabilis are long, filamentous, multinucleate cells with extremely large numbers of flagella, perhaps explaining their ability to migrate over $2 \%$ agar, which is not possible for other bacteria (Henrichsen, 1972; Rauprich et al., 1996; Fraser \& Hughes, 1999; Harshey, 2003). In contrast, other swarmers, for example those of $E$. coli, are much smaller and only moderately flagellated (McCarter, 2010). B. subtilis swarmers have been poorly characterized to date, and now we present several lines of evidence suggesting that they indeed constitute a distinctive class of cells. Thus, swarmers on B medium: (i) showed elevated hag expression, corresponding to an approximately twofold increase in flagella; (ii) were on average smaller than non-swarmers; (iii) showed low levels of comA (surfactin synthesis regulation) and eps expression compared with cells at the base of dendrites and in the MC; 
(iv) packed to a high density in dendrite tips; and (v) showed coordinated movement, forming short-lived swirling packs (Supplementary Movie File S3). Thus, in contrast to swarmers from $P$. mirabilis, $B$. subtilis swarmers are more like those described for E. coli, i.e. relatively small and with only moderate increases in flagella. Interestingly, the unexpectedly small size of $B$. subtilis swarmers could be consistent with a reduced growth rate, reflecting the diversion of resources to increasing mobility, but this remains to be tested.

\section{The importance of population density}

The correlation between hyper-mobility and a high population density raises the question of whether these are directly linked through cause and effect. In fact, some recent physical and modelling studies concerning the dynamics of suspensions of self-propelled organisms and their capacity to display coordinated movement may provide answers to this question. Thus, high-frame-rate filming (30-100 frames $\mathrm{s}^{-1}$ ) of flagellated bacteria, including laboratory strains of B. subtilis, has shown that batch-grown cells can display, specifically at high population densities in thin fluid films, a so-called cooperative or collective motion. This behaviour includes cells forming whirls and vortices capable of generating large hydrodynamic flows (Sokolov et al., 2007; Aranson et al., 2007; Tuval et al., 2005). Notably, the population densities employed in such studies are apparently similar (around $50 \%$ coverage) to those seen here at dendrite tips as well as those in E. coli swarm fronts (Darnton et al., 2010; McCarter, 2010). We suggest therefore that the high population density in dendrite tips is crucial in promoting pack formation and swirling activity.

\section{A model for dendrite elongation}

Finally, we suggest a model to explain some important features of swarming migration involving the elongation of dendrites, with a role for both swarmers and nonswarmers. The swarmers establish the radiating tracks, and this is facilitated by the modification of the agar surface by surfactin. Surfactin is known to increase the wettability of the agar (Leclère et al., 2006), consistent with, for example, the observed induced swelling of the agar surface on swarm plates, which effectively reduces the surface agar concentration (Banaha et al., 2009). The high population density in dendrite tips promotes the highvelocity collective motion of the swarmers, which in turn provides the physical force necessary to push the dendrite tips forward. On the other hand, we propose that the nonswarmers build the dendrite by growth and multiplication. Although the model still leaves much to be explained, not least the precise significance of hyper-flagellation, the switch that triggers differentiation into swarmers, the mechanism generating the high population density of swarmers, and the nature of the process ensuring radial outward expansion of dendrites and their subsequent branching, it does provide a basis for future experiments.

\section{ACKNOWLEDGEMENTS}

We are pleased to acknowledge support from Agence Nationale pour la Recherche (grant ANR-05-blan-0138), without which these studies could not have been carried out. We also acknowledge the support of Université Paris-Sud and Centre National de la Recherche Scientifique (CNRS). K. H., C. A. and D. J. are happy to acknowledge the support of student and postdoctoral fellowships from Fondation de la Recherche Médicale and Région Ile de France, respectively. M. R and R.B. are pleased to acknowledge the technical support of C. Longin. S. L. and H. P wish to thank L. Zig for excellent technical assistance. H.P. acknowledges support by funds from the CNRS (UPR 9073) and Université Paris-Diderot. We are grateful to Adrian Daerr (Department of Physics, Université Paris-Diderot) for stimulating discussions and analysis of films. We are also very grateful to $\mathrm{H}$. Vlamakis and R. Kolter (Harvard Medical School, Boston, MA, USA), and to G. Süel (University of Texas Southwestern Medical Center, Dallas, TX, USA) and M. Elowitz (California Institute of Technology, Pasadena, CA, USA), for providing us with strains and plasmids. Finally, we are very happy to indicate our particular appreciation to Noël Converset (Zeiss, France) for his enthusiastic help in establishing our image analysis systems.

\section{REFERENCES}

Abramoff, M. D., Magelhaes, P. J. \& Ram, S. J. (2004). Image processing with ImageJ. Biophotonics International 11, 36-42.

Antelmann, H., Engelmann, S., Schmid, R., Sorokin, A., Lapidus, A. \& Hecker, M. (1997). Expression of a stress- and starvationinduced $d p s / p e x B$-homologous gene is controlled by the alternative sigma factor sigmaB in Bacillus subtilis. J Bacteriol 179, 7251-7256.

Aranson, I. S., Sokolov, A., Kessler, J. O. \& Goldstein, R. E. (2007) Model for dynamical coherence in thin films of self-propelled microorganisms. Phys Rev E Stat Nonlin Soft Matter Phys 75, 040901-1R.

Banaha, M., Daerr, A. \& Limat, L. (2009). Spreading of liquid drops on agar gels. Eur Phys J Spec Top 166, 185-188.

Bisset, K. A. (1973). The zonation phenomenon and structure of the swarm colony in Proteus mirabilis. J Med Microbiol 6, 429-433.

Blair, K. M., Turner, L., Winkelman, J. T., Berg, H. C. \& Kearns, D. B. (2008). A molecular clutch disables flagella in the Bacillus subtilis biofilm. Science 320, 1636-1638.

Branda, S. S., González-Pastor, J. E., Ben-Yehuda, S., Losick, R. \& Kolter, R. (2001). Fruiting body formation by Bacillus subtilis. Proc Natl Acad Sci U S A 98, 11621-11626.

Caiazza, N. C., Shanks, R. M. \& O'Toole, G. A. (2005). Rhamnolipids modulate swarming motility patterns of Pseudomonas aeruginosa. J Bacteriol 187, 7351-7361.

Chai, Y., Kolter, R. \& Losick, R. (2009). Paralogous antirepressors acting on the master regulator for biofilm formation in Bacillus subtilis. Mol Microbiol 74, 876-887.

Chen, R., Guttenplan, S. B., Blair, K. M. \& Kearns, D. B. (2009). Role of the $\sigma^{\mathrm{D}}$-dependent autolysins in Bacillus subtilis population heterogeneity. J Bacteriol 191, 5775-5784.

Chu, F., Kearns, D. B., Branda, S. S., Kolter, R. \& Losick, R. (2006). Targets of the master regulator of biofilm formation in Bacillus subtilis. Mol Microbiol 59, 1216-1228.

Chu, F., Kearns, D. B., McLoon, A., Chai, Y., Kolter, R. \& Losick, R. (2008). A novel regulatory protein governing biofilm formation in Bacillus subtilis. Mol Microbiol 68, 1117-1127. 
Copeland, M. F., Flickinger, S. T., Tuson, H. H. \& Weibel, D. B. (2010). Studying the dynamics of flagella in multicellular communities of Escherichia coli by using biarsenical dyes. Appl Environ Microbiol 76, 1241-1250.

Cozy, L. M. \& Kearns, D. B. (2010). Gene position in a long operon governs motility development in Bacillus subtilis. Mol Microbiol 76, 273-285.

Darnton, N. C., Turner, L., Rojevsky, S. \& Berg, H. C. (2010). Dynamics of bacterial swarming. Biophys J 98, 2082-2090.

Debois, D., Hamze, K., Guérineau, V., Le Caër, J. P., Holland, I. B., Lopes, P., Ouazzani, J., Séror, S. J., Brunelle, A. \& Laprévote, O. (2008). In situ localisation and quantification of surfactins in a Bacillus subtilis swarming community by imaging mass spectrometry. Proteomics 8, 3682-3691.

Eberl, L., Molin, S. \& Givskov, M. (1999). Surface motility of Serratia liquefaciens MG1. J Bacteriol 181, 1703-1712.

Fraser, G. M. \& Hughes, C. (1999). Swarming motility. Curr Opin Microbiol 2, 630-635.

Guérout-Fleury, A. M., Frandsen, N. \& Stragier, P. (1996). Plasmids for ectopic integration in Bacillus subtilis. Gene 180, 57-61.

Hamze, K., Julkowska, D., Autret, S., Hinc, K., Nagorska, K., Sekowska, A., Holland, I. B. \& Séror, S. J. (2009). Identification of genes required for different stages of dendritic swarming in Bacillus subtilis, with a novel role for phrC. Microbiology 155, 398-412.

Harshey, R. M. (2003). Bacterial motility on a surface: many ways to a common goal. Annu Rev Microbiol 57, 249-273.

Henrichsen, J. (1972). Bacterial surface translocation: a survey and a classification. Bacteriol Rev 36, 478-503.

Julkowska, D., Obuchowski, M., Holland, I. B. \& Séror, S. J. (2004). Branched swarming patterns on a synthetic medium formed by wildtype Bacillus subtilis strain 3610: detection of different cellular morphologies and constellations of cells as the complex architecture develops. Microbiology 150, 1839-1849.

Julkowska, D., Obuchowski, M., Holland, I. B. \& Séror, S. J. (2005). Comparative analysis of the development of swarming communities of Bacillus subtilis 168 and a natural wild type: critical effects of surfactin and the composition of the medium. J Bacteriol 187, 65-76.

Kearns, D. B. \& Losick, R. (2003). Swarming motility in undomesticated Bacillus subtilis. Mol Microbiol 49, 581-590.

Kearns, D. B. \& Losick, R. (2005). Cell population heterogeneity during growth of Bacillus subtilis. Genes Dev 19, 3083-3094.

Kearns, D. B., Chu, F., Rudner, R. \& Losick, R. (2004). Genes governing swarming in Bacillus subtilis and evidence for a phase variation mechanism controlling surface motility. Mol Microbiol 52, 357-369.

Kearns, D. B., Chu, F., Branda, S. S., Kolter, R. \& Losick, R. (2005). A master regulator for biofilm formation by Bacillus subtilis. Mol Microbiol 55, 739-749.

Kobayashi, K. (2007). Bacillus subtilis pellicle formation proceeds through genetically defined morphological changes. J Bacteriol 189, 4920-4931.

Kobayashi, K. (2008). SlrR/SlrA controls the initiation of biofilm formation in Bacillus subtilis. Mol Microbiol 69, 1399-1410.
Leclère, V., Marti, R., Béchet, M., Fickers, P. \& Jacques, P. (2006). The lipopeptides mycosubtilin and surfactin enhance spreading of Bacillus subtilis strains by their surface-active properties. Arch Microbiol 186, 475-483.

Lemon, K. P., Earl, A. M., Vlamakis, H. C., Aguilar, C. \& Kolter, R. (2008). Biofilm development with an emphasis on Bacillus subtilis. Curr Top Microbiol Immunol 322, 1-16.

López, D. \& Kolter, R. (2010). Extracellular signals that define distinct and coexisting cell fates in Bacillus subtilis. FEMS Microbiol Rev 34, 134-149.

Lynch, D., O’Brien, J., Welch, T., Clarke, P., Cuív, P. O., Crosa, J. H. \& O'Connell, M. (2001). Genetic organization of the region encoding regulation, biosynthesis, and transport of rhizobactin 1021, a siderophore produced by Sinorhizobium meliloti. J Bacteriol 183, 2576-2585.

Marrocco, A., Henry, H., Holland, I. B., Plapp, M., Séror, S. J. \& Perthame, B. (2010). Models of self-organizing bacterial communities and comparisons with experimental observations. Math Model Nat Phenom 5, 148-162.

McCarter, L. L. (2010). Bacterial acrobatics on a surface: swirling packs, collisions, and reversals during swarming. J Bacteriol 192, 3246-3248.

Nakano, M. M., Corbell, N., Besson, J. \& Zuber, P. (1992). Isolation and characterization of $s f p$ : a gene that functions in the production of the lipopeptide biosurfactant, surfactin, in Bacillus subtilis. Mol Gen Genet 232, 313-321.

Patrick, J. E. \& Kearns, D. B. (2009). Laboratory strains of Bacillus subtilis do not exhibit swarming motility. J Bacteriol 191, 71297133.

Rashid, M. H. \& Kornberg, A. (2000). Inorganic polyphosphate is needed for swimming, swarming, and twitching motilities of Pseudomonas aeruginosa. Proc Natl Acad Sci U S A 97, 4885-4890.

Rauprich, O., Matsushita, M., Weijer, C. J., Siegert, F., Esipov, S. E. \& Shapiro, J. A. (1996). Periodic phenomena in Proteus mirabilis swarm colony development. J Bacteriol 178, 6525-6538.

Sokolov, A., Aranson, I. S., Kessler, J. O. \& Goldstein, R. E. (2007). Concentration dependence of the collective dynamics of swimming bacteria. Phys Rev Lett 98, 158102-158106.

Turner, L., Zhang, R., Darnton, N. C. \& Berg, H. C. (2010). Visualization of flagella during bacterial swarming. J Bacteriol 192, 3259-3267.

Tuval, I., Cisneros, L., Dombrowski, C., Wolgemuth, C. W., Kessler, J. O. \& Goldstein, R. E. (2005). Bacterial swimming and oxygen transport near contact lines. Proc Natl Acad Sci U S A 102, 2277-2282.

Vlamakis, H., Aguilar, C., Losick, R. \& Kolter, R. (2008). Control of cell fate by the formation of an architecturally complex bacterial community. Genes Dev 22, 945-953.

Zhang, R., Turner, L. \& Berg, H. C. (2010). The upper surface of an Escherichia coli swarm is stationary. Proc Natl Acad Sci U S A 107, 288-290.

Edited by: T. Msadek 